\title{
Exploring the Internetization of Private Finance
}

\author{
Kong Yan ${ }^{1}$, Wang Yanna ${ }^{1, *}$, and Cai Jieping ${ }^{1}$ \\ ${ }^{1}$ School of Economics and Trade, Guangzhou Xinhua University, Guangzhou, China
}

\begin{abstract}
Following the two stages of booming and tightening supervision, Internet-based private finance is now exhibiting a slowdown in its development. Within the framework of the transaction cost theory, this study explores the motivations for and the boundaries of new business forms, and proposes that their continuous changes in the risk management mechanism, legal relations between transaction entities, and capital operation models have raised financial risks while elevating their own financial availabilities. The author then concentrates on the three core functions that stem from the functional financial theories and analyses the risks private finance has to take during its Internetization from the perspectives of capital flow and information flow. In the end, suggestions have been made from two aspects, the risk early warning and the combination of flexible and forceful supervision. The author points out that Internet-based private finance is an inevitable trend in the future. We should solve the existing problems and refrain from being held back for fear of a slight risk.
\end{abstract}

\section{Introduction}

With a long history in China, private finance dates back to the Western Zhou Dynasty. The form of its existence also changes according to the external environment. With the rapid development of the Internet and a gradually growing user base, private finance and the Internet started to intersect with each other, demonstrating an extensive "barbaric growth" model. The concept of Internetization was put forward by Analyses International in 2007. According to this concept, the Internet will be turned into a ubiquitous infrastructure in the future. Enterprises will exploit the Internet, both the platform and technology, to conduct internal and external business activities and, as a result, to integrate resources and interact with each other. Based on such a concept, the author believes that the finance Internet has developed from only with physical forms to a virtual existence, expanding the boundary of interest rates and marketized capital transactions. Accordingly, the Internetization of private finance is different from that and credit activities based on kinship and community ${ }^{[1]}$

The Internetization of private finance has been through ups and downs over rather past decade. In the first five-year, financial innovations were booming, with platforms of various kinds being created, enriching the catalogue of financial products and expanding service channels. Investors were flocking to those platforms. In the second five-year, the focus was shifted to financial risk prevention and control. Financial frauds kept emerging, bringing bad reputations to private finance. While providing new impetus for China's economic development, the Internetization of private finance also raises new questions for the development and supervision of the country's financial market. Based on previous research on the Internetization of private finance, the author attempts to summarize its operating characteristics, carry out targeted utility analysis, explore the concept from the perspective of risk prevention and control and finally, proposed suggestions for its future development.

\section{Motivations for and Boundaries of Private finance Internetization}

According to the transaction cost theory, the market uses prices as signals to allocate resources ${ }^{[2]}$. When the resources allocation is done by enterprises or organizations, the transaction cost can be lowered, including the fees for obtaining market information, negotiation and recurring contracts. In case excessively high transaction fees are generated through market resource allocation, companies that can provide services of lower prices start to pop up in the market. Due to financial repression and information asymmetry, some fund-seeking economic entities (private SMEs and individuals) fail to secure financial support from mainstream financial institutions, giving birth to private finance. Table 1 compares the transaction costs for private SMEs and individuals when dealing with mainstream financial institutions (represented by banks) and informal financial institutions. From the table, we can conclude that as an intermediary connecting the suppliers and demanders of capital, private finance, coupled with local traditional culture, forms constraints of social capital, gains a competitive edge and secures its place in the market by lowering transaction costs.

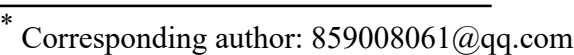


Table 1. Comparison of transaction costs between banks and private financial institutions

\begin{tabular}{|c|c|c|}
\hline & Banks & $\begin{array}{l}\text { Private financial } \\
\text { institutions }\end{array}$ \\
\hline $\begin{array}{l}\text { Information } \\
\text { cost }\end{array}$ & $\begin{array}{l}\text { High expenditure } \\
\text { of time and } \\
\text { money required to } \\
\text { obtain the } \\
\text { creditor's } \\
\text { information such } \\
\text { as the credibility, } \\
\text { income, and loan } \\
\text { repayment ability }\end{array}$ & $\begin{array}{l}\text { Lower costs for } \\
\text { transactions based } \\
\text { on geographical, } \\
\text { blood, and } \\
\text { interpersonal } \\
\text { relations }\end{array}$ \\
\hline $\begin{array}{c}\text { Cost of } \\
\text { financial } \\
\text { supervision }\end{array}$ & $\begin{array}{l}\text { Under strict loan } \\
\text { control, with } \\
\text { complicated } \\
\text { borrowing } \\
\text { procedures and } \\
\text { high loan } \\
\text { guarantee costs }\end{array}$ & $\begin{array}{l}\text { Free from financial } \\
\text { regulation by the } \\
\text { government, with } \\
\text { simple procedures } \\
\text { and flexible loan } \\
\text { guarantees }\end{array}$ \\
\hline $\begin{array}{c}\text { Transaction } \\
\text { cost }\end{array}$ & $\begin{array}{l}\text { High costs on the } \\
\text { repayment ability } \\
\text { of the guarantors }\end{array}$ & $\begin{array}{l}\text { The credibility and } \\
\text { reputation } \\
\text { mechanism } \\
\text { stemming from } \\
\text { traditional Chinese } \\
\text { culture have } \\
\text { lowered the } \\
\text { supervision costs } \\
\text { and avoided } \\
\text { breaches of } \\
\text { contract }\end{array}$ \\
\hline $\begin{array}{l}\text { Litigation } \\
\text { cost }\end{array}$ & $\begin{array}{c}\text { Expensive } \\
\text { ligation fees and } \\
\text { prolonged } \\
\text { litigation periods }\end{array}$ & $\begin{array}{l}\text { Ensure contract } \\
\text { execution with } \\
\text { community rules or } \\
\text { even compulsory } \\
\text { means to avoid the } \\
\text { higher costs of } \\
\text { legal means }\end{array}$ \\
\hline
\end{tabular}

The boundaries for corporate behaviour are determined by comparing the costs of organizing a transaction by an enterprise and by the market. The advantage of private finance lies in its access to a lower unit financial cost ${ }^{[3]}$. However, its development is also constrained by economies of scale and scope. First of all, the behavioural boundaries of private finance continue to expand. As the supply and demand of capital increase rapidly, sharp rises can be seen from the information costs and transaction costs until they reach a tipping point, after which private finance no longer has cost advantages over mainstream financial institutions. The marginal cost of borrowings of private finance demonstrates a U-shaped in the curve graph, first declining and then rising. Therefore, the marginal cost of borrowings serves as a key factor in the Internetization of private finance. This explains why informal financial institutions are largely based on geographical and interpersonal relations. As the geographical area expands and the borrowers increase, stronger asset management will be needed, leading to a sharp increase in the transaction costs, hence reducing the revenue or even render the loans unprofitable.

The curve graph for marginal costs of borrowings for private finance and mainstream financial institutions can be seen in Figure 1. As seen from the figure, two curves intersect at point $\mathrm{M}$. On the left side, the marginal cost for private finance is lower than mainstream financial institutions, while on the right side, this strength of private finance no longer exists.

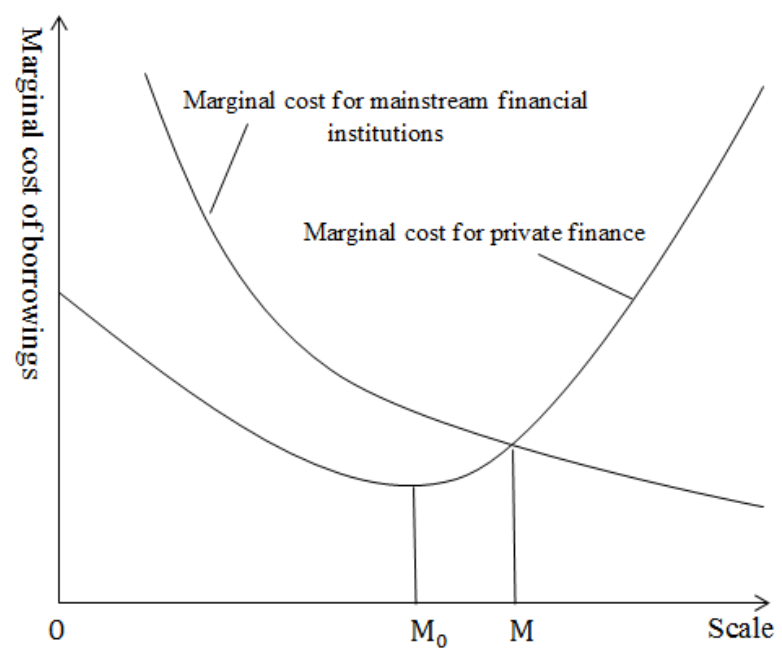

Fig. 1. Marginal cost of borrowings for formal and private finance

The profit-seeking nature of capital seeks a larger market. On the supply side of private finance exists a large number of private enterprises, non-corporate entities, and individuals with a strong desire to invest in the market. On the demand side, among the current economic slowdown, private enterprises and individuals crave investments. As the Internet technology gradually matures, the transaction costs and information asymmetry will be reduced, and the transaction and management efficiency will be elevated. With a few simple financial services, operational platforms build Internet-based and mobile financial facilities, reducing the company's need for physical outlets, uplifting the restrictions posed by geographical and interpersonal relations and improving the service quality. The advancement and popularization of the Internet technology serve as one of the internal motivations for the Internetization of private finance, pushing the boundaries of financial market transactions to a large extent $^{[4]}$.

\section{Operation of Private finance Internet}

After an internet was constructed within the industry, informal financial institutions have been innovating their business models. Though the financial and risk-entailed properties of investment and finance can never be changed, they did change the risk management mechanism in the system, the legal relationship between transaction participants and the way capital operates within the market.

\subsection{Changes in risk management mechanism}

Within private finance of the traditional sense, the participants are of a single nature, and most transactions 
happen between two natural persons and between natural persons and enterprises. The number of participants is very limited, which means the transactions are restricted within a small community formed by acquaintances. The stable credibility and reputation mechanisms, public opinions and even coercive means formed by traditional social capitals, have restrained the credit behaviours, and lower the risk of contract defaults with a risk management mechanism that handles "soft information" "[5].

Following the Internetization of private finance, the borders of financial transactions have expanded, from an acquaintance-formed stable community to a regional community with diverse immigrant cultures. The growing transaction participants and the complicated transaction types call for establishing a system and infrastructure to prevent credit risks and also a reasonable "hard information" mechanism to protect the participants' privacy.

\subsection{Changes in the legal relationships between transaction participants}

Private finance in a traditional sense represents the single debtor-creditor relation between the lenders and borrowers. Following the Internetization, the number of participants in the transaction has increased, including the borrowers, lenders, operational platforms, third-party payment platforms and vouching organizations. Four legal relationships were formed among these participants.

(1) The debtor-creditor relationship between the lenders and borrowers. The loan contracts signed between natural persons, natural persons and nonfinancial enterprises, natural persons and legal persons, as well as natural persons and other organizations, can be defined as informal debtor-creditor legal relations.

(2) The intermediary relationship among the borrowers, lenders and operational platforms. During the transaction process, operational platforms serve as intermediaries and provide venues and services for smooth transactions between the lenders and borrowers.

(3) The vouching relationship among the vouching companies, lenders and borrowers. In case no vouching services would be provided by the operational platforms, to reduce transaction risks and expand the business scope, the operational platforms may cooperate with vouching companies to provide this kind of service to the lenders.

(4) The payment relationship among the borrowers, lenders, operational platforms and the third-party payment platforms. This kind of regal relation is way more complicated than those of private finance of the traditional sense. Currently, it has encountered some obstacles in the legal system. It makes it extremely difficult to protect the investor's money.

\subsection{Changes in the way capital operates within the market}

Private finance based on geographical and interpersonal relationships has demonstrated a consistency in capital flow, information flow and business flow. The borrowed funds can be used for industrial production or individual needs. Since the year 2008, three deflections have shown up in China's macroeconomy: the deflection of currency rates away from economic performance; the deflection of financial growth away from high investment efficiency; the deflection of fast-growing asset values from low commodity prices. As a result, the virtual economy has been booming, with social capital flooding to the stock market and real estate market. The capital idly flows within the financial system without generating any actual values, raising the financing costs in the real economy. In such an environment, the misallocation of financial resources and improper risk management in the private finance Internet has turned the debtor-creditor model into a social investment behaviour and capital has descended to a tool merely for arbitrage ${ }^{[6]}$.

\section{Risk Analysis of Private finance Internetization from the Perspective of Functional Finance Theory}

Internet-based private finance combines the Internet with finance. The properties as the finance still trump over the those of the Internet. Finance is a kind of resource allocation that can transcend time and space. Risks, however, arise during such transcendence of time and space. The highly efficient financial services based on the Internet have become an essential part of the economy. Objectively speaking, the lack of supervision and self-discipline have contributed to the current vulnerability of the financial industry. Therefore, risk management should be considered a core task.

Traditional financial theories explored the financial system based on the functions of financial institutions. The certainty of existing financial market participants should comply with relevant laws and regulations. At the same time, problems with the framework would be solved by maintaining the stability of the original financial system. These theories ignored the fact that changes in the external environment and technological advances have impacts on the financial market and its participants. Market operation will become less efficient and orderly when new business forms are created ahead of relevant laws and regulations.

According to the functional finance theory, financial functions are more stable and important than financial institutions. Based on this assumption, advocates of the theory proposed three core functions for a financial system: payment function, resource allocation function and risk diversification function. In the fields of investment and financing, the three core functions of a financial system are expressed as goals for asset appreciation. Two things should be guaranteed to achieve these goals, a long-term and stable cash flow and credit maximization. Therefore, the author of this paper will focus on these three core functions and analyse the risks of private finance Internetization from the angles of capital flow and information flow. 


\subsection{Payment function}

The payment function of traditional private finance arises from the separation of time and space during the settlement of claims and debts. Internet technology has shattered the restrictions of time and space. As an essential component of Internet-based private finance, third-party payment has gained rising significance not just because of its role as a capital flow channel, but also because of its characteristic of financial value-added ${ }^{[7]}$. The rapid development of third-party payment gave rise to some issues concerning legal affairs and network security. Risks are standing in the way of third-party payment.

(1) Risk of fund deposition

Time gaps exist between the payment and receipt of funds when the transaction is conducted on a third-party payment platform. A large sum of money has been deposited on the payment platform. The amount will be massive as the business expands. Companies that own those platforms won't open an interest-free account in banks to deposit those funds. Instead, they may even absorb the interest generated by the deposited funds as one of their income sources. As stipulated by the Law of the People's Republic of China on Commercial Banks, any individual or institution is forbidden to illegally absorb public deposits in any way. Though the "Detailed Rules for the Implementation of the Administrative Measures for the Payment Services Provided by Nonfinancial Institutions" stipulated that third-party companies should pay a certain amount of security deposit. However, if problems arise with the third-party payment companies, for example, when their credit scores have declined, the levels of fund security of the platform will also decline.

(2) Risk of money laundering

Third-party payment platforms provide services for both parties of the transaction with the help of Internet technology. The financial supervision of those platforms, however, is insufficient at the current moment. It is very difficult for third-party payment platforms to identify both parties of the transaction. They don't have the means to detect and monitor malicious transactions, so it is hard for them to identify the actual capital flows.

(3) Risk of information leak

The virtuality, openness, high-tech and digitalization of the Internet are the most important roots for online privacy and security issues. After the transaction is completed, both parties will leave behind certain information on the payment platform. These personal data are protected by an individual's property rights and privacy rights. At the same time, they can also be used for generating commercial value. Users' information is at risk of being leaked.

\subsection{Resource allocation function}

Internet-based private finance has given competitive edges to capital suppliers. Amid the current economic downturn, low rates can be seen in the return on investment (ROI) for the real economy. With the help of Internet financial platforms such as $\mathrm{P} 2 \mathrm{P}$, private finance promises a higher return rate of over $10 \%$. The resources, in fact, are misallocated. Most of the funds flow to highrisk fields, such as the real estate and security industries, or becomes a source of bad debts. Some of them have even been used for advertising and supporting excessive consumption. In the absence of financial supervisors, the following risks are faced by the borrowers, investors and Internet financial platforms.

(1) Risk of illegal fundraising

The existence of intermediate capital pools gave rise to a phenomenon in which fund transfers precede investment behaviours. The investment risks brought by unclear fund use, embezzlement, financial frauds that violate the investor's interests and the lack of supervision that jeopardizes financial stability, are closely related to the intermediate capital pools.

(2) Risk of liquidity and securitization

For professional lenders in debt transfer models, their accounts are under great liquidity pressure due to the mismatches of contract terms and sums of money. If the creditor's rights fail to be transferred to the next creditor within the specific time frame, cash flow breakage may arise. Another risk related to this is whether the transfer of these credit assets constitutes an act of securitization, and whether the risk is already known to the public.

(3) Risk of financial disclosure

In fact, even though Internet financial companies have released their financial statements, their financial status may not be fully disclosed. As intermediaries for transactions, financial platforms are not involved in the debtor-creditor relationship, so the bad debt ratios of the platforms will not be included in their financial statements.

\subsection{Risk diversification function}

Risk diversification means improving the welfare of enterprises and families by providing wealth management solutions. Enterprises and families can choose the risks they are willing to bear and avoid those they want to shrink from. Therefore, the risk diversification function of the Internet-based private finance is reflected in two aspects: first, small-amount assets are put under management to develop client base downstream; second, an efficient and convenient wealth management network is provided, adding a new function to wealth management and expanding transaction possibilities.

The expansion of transaction possibilities and the interconnectivity of the Internet itself may amplify the effect of "long-tail" liabilities. The clients are large in number, yet they only invest a small sum of money. Most of the clients are not equipped with relevant financial knowledge to help them identify risks. The herding phenomenon, mostly taking the form of individual or collective irrational behaviour, can be easily created by causing sensations on the ubiquitous Internet. As a result, credit risks and liquidity risks spread through the transaction participants, leading to possible capital loss and even systematic risks. 


\section{Suggestions and Future Prospects}

The Internetization of private finance is an open-ended and highly controversial issue. The mechanism and nature of finance decide that risks are embedded in every financial model and product. China's financial industry has always been developing and innovating under government supervision. Following booming and tightening supervision stages, Internet-based private finance is bound to enter a new stage of standardized and healthy development. Comprehensive and systematic research should be conducted on every new financial business form. Also enough attention shall be paid to the early warning of risks, and flexible yet forcible supervision should be executed to avoid any one-sizefits-all approaches ${ }^{[8]}$.

First, the government will establish a supervision model that fits the Internet-based private finance. In China, private finance is jointly supervised by multiple ministries or departments, including The People's Bank of China, the China Banking and Insurance Regulatory Commission, the China Securities Regulatory Commission as well as local governments at all levels. Businesses concerning the Internet can transcend the boundaries of markets and industries. Their business forms can also intersect with each other. The supervision means in the traditional financial model may cause loopholes or overlap in management, which will in turn result in an institutional mismatch between mixed management and separate operation supervision. A coordinated regulation model shall be established concentrating on industry self-regulation and supplemented with government supervision ${ }^{[9]}$. Supervision activities shall be conducted by industry associations on a regular basis, using the industry's selfregulation ability to ensure smooth operations of private finance. On the other hand, government regulatory bodies implement relevant laws and regulations, ensure the legitimacy of industry regulations, and comply with the general principles of regulation to avoid overregulation.

Second, financial regulatory authorities should improve the risk early warning capabilities. From the temporal dimension, countercyclical financial regulation shall be conducted, while from the space dimension, the contagion paths shall be under strict control to avoid systematic risks. The cross-border, disintermediating, distributed and intelligent Internet-based private finance has brought cross-border and mixed management, leading to risks that are hard to detect and easy to spread at a fast speed. On the other hand, system design concerning information security, credit rating and risk control fail to catch up, resulting in accumulating unsolved risks in the system. Therefore, early risk warning and prior management would be the effective means. If we want to detect systematic financial risks, we must accelerate the informatization and database construction for financial supervision. The credit system, payment and clearing systems as well as their ability to collect information shall be improved. Moreover, the information system integration and sharing shall be strengthened both within the financial regulatory authorities and between various economic sectors.

\section{Conclusion}

The trend of Internet-based private finance has been increasing in recent years, in addition to the official financial system of China, private finance independently forms a self-recycling financial system. In the meanwhile of the effective improvement of the longtailed market financial availability, promoting financial deepening, improving financial efficiency and promoting regional economic growth, the Internet of private finance intensified the capital out of reality, increased the difficulty of financial risk prevention and control, magnified the private financial risks. Through the advanced private financial risk management concept to establish the private financial current own development of risk content, improve the private financial management situation, strengthen the private financial management methods, so as to create the private financial core risk management mode, to achieve the sustainable development and competitive advantage of the private finance under the Internet.

\section{Acknowledgment}

The authors are grateful for the financial support of the 2016 Department of Education of Guangdong Province Key Discipline "Public Administration" research project; the Major Project of Basic Research and Applied Research in Guangdong Province (Social Sciences Category) (2017WZDXM037) ; the Youth Innovation Project of Key Platform of Colleges and Universities in Guangdong Province (2016WQNCX188) ; and the Project of Teaching Team of Internet Finance Course (2019T002) in Xinhua College of Sun Yat-sen University.

\section{References}

1. An Q.S., Hu J.Y., Jiang Z.Y. Internet of Private finance: Reflections on Reality and Theoretical Thinking [J]. Economist, 2017(10). 86-95

2. Jiang X.Z., Ding C.F. The Analysis of Private finance Theory: Scope, Comparison and Institutional Transition[J]. Financial Research, 2014(8). 100-111

3. Xie P., Zou C.W., Liu H.E. The Fundamental Theory of Internet Finance[J]. Financial Research, 2015(8). 1-12

4. Li J.Z. Thoughts on Internet Finance [J] Management World, 2015(7). 16-20

5. Lin Y.F., Sun X.F. Information, Private finance and SME Financing [J]. Economic Research Journal, 2005(7). 35-44

6. Zheng L.S. Internet Finance in China: Model, Influence, Nature and Risks [J]. International Economic Review, 2014(5). 103-118+6 
7. Wang L.X. Risks of Third-Party Payment in the Era of Internet Finance [J]. Commercial Times, 2017(17). 154-156

8. Xu B.L. Internet Financial Governance System and Optimization Strategy $[\mathrm{J}]$. Technoeconomic and Management Research, 2020(4). 91-95

9. Sun H.Y. Definition, Risks and Preventive Measures of Internet Finance[J]. Commercial Times, 2016(1). 170-171 